\title{
Palliative care as an emerging role for respiratory health professionals: Findings from a cross-sectional, exploratory Canadian survey
}

\author{
Donna Goodridge, RN, $\mathrm{PhD}^{1}$, Jaimie Peters, RN, MN, CRE ${ }^{2}$
}

\begin{abstract}
D Goodridge, J Peters. Palliative care as an emerging role for respiratory health professionals: Findings from a cross-sectional, exploratory Canadian survey. Can J Respir Ther 2019;55:73-80. doi: 10.29390/cjrt-2019-010.

Introduction: Respiratory Health Professionals (RHPs) with specialty training in the management of asthma and COPD, often care for patients with advanced respiratory disease, who have less access to palliative care than patients with similar disease burden. The aims of this study were to: $(i)$ explore the current and desired roles of RHPs in terms of palliative care and (ii) examine barriers to discussions with patients about palliative care.

Methods: An online survey addressing the aims of this study was developed and pilot tested. The survey was distributed nationally using the database of the Lung Association's RESPTREC respiratory educator training program. Descriptive statistics were performed.

Results: A total of 123 completed surveys were returned, with respiratory therapists comprising the largest group of respondents. The majority indicated that end-of-life care was less than optimal for patients with advanced respiratory illnesses and agreed that palliative care should be a role of RHPs. Patientand family-related barriers to having end-of-life discussions included: difficulty accepting prognosis, limitations and complications, and lack of capacity. For providers, the most important barriers were: lack of training, uncertainty about prognosis, and lack of time. The health care system barriers of concern were increasing demand for palliative care services and limited accessibility of palliative care for those with advanced respiratory diseases and difficulties in accurate prognostication for these conditions.

Discussion: Incorporating a more defined role in palliative care was generally seen as a desirable evolution of the RHP role. A number of strategies to mitigate identified barriers to discussions with the patient are described. Better alignment of the services required with the needs of patients with advanced respiratory disease can be addressed in a number of ways.

Conclusions: As RHP roles continue to evolve, consideration should be given to the ways in which RHPs can contribute to improving the quality of care for patients with advanced respiratory disease. Building collaborations with RHPs, palliative care, and other existing health programs can ensure high quality of care. Creating and taking advantage of learning opportunities to build skills and comfort in using a palliative approach will benefit respiratory patients.
\end{abstract}

Key Words: Palliative care; End-oflife care; advanced respiratory disease; COPD; advanced care planning; respiratory health professionals; certified respiratory educators; Medical Assistance in Dying

\section{INTRODUCTION}

Chronic respiratory diseases are currently the fifth leading cause of death in Canada [1]. The Conference Board of Canada [2] forecasts that the prevalence of chronic lung diseases will increase by $32 \%$ (1.6 million cases) between 2010 and 2030, primarily reflecting the growing number of older adults living with Chronic Obstructive Pulmonary Disease (COPD) or lung cancer. Deaths due to idiopathic pulmonary fibrosis are steadily increasing worldwide [3], while pulmonary arterial hypertension [4] and cystic fibrosis [5] are well-recognized as life-limiting illnesses. Symptoms commonly experienced in advanced respiratory diseases include: dyspnea, cachexia, hemoptysis, fatigue, cough, psychosocial discomfort, and pain [6].

Around the world, demographic and disease trends are transforming the landscape of health care needs. In 2017, over 275,000 Canadians died [7], a number that will continue to increase as the population grows and ages. It is estimated that between $62 \%$ and $89 \%$ of all those who die would benefit from palliative care [8]. Of people who died in Canadian hospitals, a 2018 report by the Canadian Institute of Health Information (CIHI) suggested that $94 \%$ may have benefited from palliative care services [9], although these services are not universally accessible.
Palliative care is defined as "the active holistic care of individuals across all ages with serious health-related suffering due to severe illness, and especially those near the end of life" [10]. Palliative care can be provided alongside disease-modifying treatments and supports patients to live as fully as possible until death. Palliative care includes "prevention, early identification, comprehensive assessment and management of physical issues...psychological distress, spiritual distress and social needs" [10]. Access to palliative care services has been associated with the following improved outcomes: greater patient satisfaction with care [11, 12], decreased symptom burden [13, 14], fewer emergency department visits $[9,15,16]$, reduced hospital admissions [15], reduced lengths of stay [15], 30-day re-admissions $[16,17]$, reduced likelihood of admission to the intensive care unit [9], less likelihood of avoidable hospital transfers from long-term care [9], and a greater likelihood of dying at home [9]. These potential outcome improvements warrant closer examination of the ways in which palliative care might contribute to care of patients with advanced respiratory diseases.

Although the need for palliative care for patients with advanced respiratory disease is increasingly recognized [18-20], these services are often conspicuously inaccessible for this population [21, 22]. Noncancer deaths are responsible for more than two-thirds of all deaths in Canada [23, 24],

${ }^{1}$ College of Medicine, Repiratory Research Centre, University of Saskatchewan, Saskatoon, SK

${ }^{2}$ Lung Association of Saskatchewan, Saskatoon, SK

Correspondence: Donna Goodridge, College of Medicine, Respiratory Research Centre, University of Saskatchewan, Room B523 Health Sciences Building, 107

Wiggins Road, Saskatoon, Saskatchewan, S7N 5E5, Canada. Tel: 306-966-4209; E-mail: donna.goodridge@usask.ca

Published online at https://www.cjrt.ca on 16 September 2019

This open-access article is distributed under the terms of the Creative Commons Attribution Non-Commercial License (CC BY-NC) (http:// creativecommons.org/licenses/by-nc/4.0/), which permits reuse, distribution and reproduction of the article, provided that the original work is properly cited and the reuse is restricted to noncommercial purposes. For commercial reuse, contact editor@csrt.com 
yet cancer patients were found to be three times more likely to receive palliative care, either in hospital or at home, than Canadians with other diagnoses [9]. While symptom burden, care trajectories, and health status can be similar, the quality and access to palliative care of those with advanced Chronic Obstructive Pulmonary Disease (COPD) has been reported to be relatively poor compared to those with lung cancer [18, 25]. Patients with COPD receive more aggressive treatment at the end of life and less palliative care than those with lung cancer, even though they report similar preferences for palliative care [26]. In a study of place of death in 14 countries, Cohen et al. [27] found that those dying from COPD were less likely to die at home or in a palliative care setting and more likely to die in a hospital or nursing home than patients dying from lung cancer. The palliative care needs of patients with Interstitial Lung Disease are strikingly similar to those in malignant disease [28], but palliative care services for this group are only now being developed.

Three types of barriers to accessing palliative care for patients with advanced respiratory diseases have been identified. These include barriers relating to: (i) health care providers, (ii) health care systems, and (iii) patients themselves. Providers have reported insufficient time and (or) skills to discuss palliative care, as well as concerns that such discussions might diminish hope [29, 30]. Implicit bias on the part of providers against patients with smoking-related respiratory diseases may contribute to decreased accessibility of palliative care, especially when patients continue to smoke [31]. The increasing demand for palliative care services within health care systems [32, 33] limits accessibility for those with advanced respiratory diseases, as do the difficulties in accurate prognostication for these conditions $[34,35]$. The stigma and guilt associated with smoking may cause some patients to delay seeking diagnosis and treatment. Patients may also fear abandonment by their usual health care team if they access palliative care services $[6,29]$ or they may hold negative attitudes towards palliative care $[35,36]$.

Despite these challenges, new models integrating palliative care and chronic disease management for patients with advanced respiratory disease have reported positive outcomes. Examples of novel services include: patient-centred medical homes [37], breathlessness services that provide early access to palliative care [38, 39], and an Advanced Lung Disease Service [40]. Within Canada, the INSPIRED COPD Outreach Program $^{\mathrm{TM}}[41]$ and the subsequent pan-Canadian care collaborative [42] reported rapid changes to work practices, cultural change, and skills sets at relatively low cost. Common to these new programs is an interdisciplinary approach.

Across Canada, Medical Assistance in Dying (MAiD) became law through Bill C-14 in 2016, providing another end-of-life care option for eligible Canadian adults with a "grievous and irremediable medical condition" who make a voluntary request and can provide informed consent [43]. Nurse practitioners and physicians can legally administer MAiD services in Canada [43]. Up until 31 October 2018, 6749 Canadians have opted for MAiD, with circulatory/respiratory disease noted as the underlying medical circumstance in between $11 \%$ and $17 \%$ of cases [44].

Respiratory health professionals (RHPs) such as respiratory therapists, nurses, pharmacists, and rehabilitation therapists often receive specialty training in asthma and COPD chronic disease management to become Certified Respiratory Educators (CREs). CREs educate clients about their asthma or COPD and motivate them to self-manage their disease. CREs are trained how to assess patient knowledge, desires, and acceptance of prognosis [45], although these supports are often provided by professionals without CRE specialty training. Many patients, however, may not have access to this education and support [46, 47]. RHPs with chronic disease management knowledge clearly make significant contributions to the care of patients with advanced respiratory diseases, although their involvement in providing palliative care in Canada has not been clearly articulated.

The aim of this cross-sectional study was to explore the current and desired roles of RHPs in the palliative care of patients with advanced disease and to examine barriers to having discussions with patients related to palliative care faced by these providers. The findings of this initial study were intended to provide direction for further research into the roles of RHPs in palliative care.

\section{METHODS}

Approval to conduct the study was granted by the University of Saskatchewan Behavioural Research Ethics Board (BEH\# 18-147). A search for publications related to RHPs' perceptions of and involvement in palliative care did not identify existing questionnaires that could address the aims of this study. The authors developed a 27 -item survey suitable for online administration based on key concepts identified from the literature review. Fourteen additional items elicited salient demographic and professional characteristics. The survey was pilot tested with three RHPs for clarity and content. Minor revisions were made to the survey. The online survey was hosted through Voxco and consent was presumed if the individual completed the survey. Because we were interested in gaining a wide spectrum of perspectives on desired roles, individuals who did not currently provide palliative care for respiratory patients were eligible to participate.

Definitions of palliative care were provided at the beginning of the survey, along with the following three questions reported in the literature [8] that could help participants consider whether patients with advanced respiratory disease could be considered to be close to the end of life: (i) "Would you be surprised if your patient died within the next year?", (ii) "Does your patient show general indicators of decline?" (e.g., repeated, unplanned hospital admissions; presence of significant co-morbidities), and (iii) "Does your patient have at least two respiratory-specific indicators of advanced disease?" (e.g., eligible for long-term oxygen, Medical Research Council (MRC) grade 4 or 5).

The survey was comprised of four sections and included: (i) Likerttype items that measured level of agreement with a range of statements salient to current and preferred practice and roles in palliative care of patients with advanced respiratory disease and (ii) fixed-choice items eliciting preferences regarding care, barriers to enacting palliative care roles, and the characteristics of current educator practices. Demographic items addressed professional, training, and geographic attributes.

Surveys were electronically distributed in English to 3204 RHPs from across Canada on the RESPTREC mailing list in September, 2018, for a period of 30 days. The RESPTREC mailing list consists of all health professionals who have taken a minimum of one respiratory educator course from this program since 2001. RTs comprise 39\% of the list, while nurses, pharmacists, and others (therapists and dieticians) make up 36\%, 13\%, and $12 \%$, respectively. Consent to participate was implied by completion of the survey and a full description of the intent of the survey was provided. A reminder e-mail was sent out after 1 week. Responses were anonymous and returned to the social sciences research laboratory.

Descriptive and univariate analyses were conducted based on 123 completed surveys using SPSS v. 25 in consultation with a statistician. Multilevel responses to the survey items were dichotomized for clarity of interpretation. Frequencies were computed for all variables and presented as observed/totals and percentages. Associations were examined using cross-tabulation, $\chi^{2}$, or Kruskal-Wallis ANOVA statistics as appropriate. The significance level was set a priori at 0.05 . Surveys missing in excess of $50 \%$ of item responses were not included in the analyses. While there were relatively few missing responses to the survey, average imputation was used, whereby the mean for the sample for that item was used.

\section{RESULTS}

Three hundred and five individuals opened the survey and 123 RHPs completed the entire survey, for an in-scope response rate of $40.3 \%$ and an overall response rate of $3.8 \%$. Respiratory therapists (RTs) accounted for $87(70.7 \%)$ of respondents, while nurses $(n=19 ; 15.4 \%)$, pharmacists $(n=5 ; 4.1 \%)$, physiotherapists $(n=4 ; 3.3 \%)$, and other health professionals $(n=8 ; 6.5 \%)$ accounted for the remainder. Given the uneven distribution of professional designations, this category was collapsed into RTs $(n=87)$ and other respiratory health professionals $(n=36)$ for purposes of statistical analyses.

Table 1 provides an overview of demographic, personal, and employment characteristics of respondents. Chi-square and Kruskal-Wallis ANOVA analyses were performed as appropriate and no significant differences could be detected between RTs and other RHPs on any variable. 
TABLE 1

Demographic, personal, and employment characteristics of respondents $(n=123)$.

\begin{tabular}{|c|c|c|c|c|}
\hline Characteristics & $\begin{array}{l}\text { No. }(\%) \text { Respiratory } \\
\text { Therapists, }(n=87)\end{array}$ & $\begin{array}{c}\text { Other respiratory } \\
\text { professionals }(n=36)\end{array}$ & $\begin{array}{l}\text { Overall } \\
n=123\end{array}$ & $p$ \\
\hline \multicolumn{5}{|l|}{ Gender } \\
\hline Female & $73(83.9)$ & $35(97.2)$ & $108(87.8)$ & NA \\
\hline Male & $14(16.1)$ & $1(2.8)$ & 15 (12.2) & NA \\
\hline \multicolumn{5}{|l|}{ Geographic location } \\
\hline Western Canada & $39(44.8)$ & $19(52.8)$ & $58(50.1)$ & 0.61 \\
\hline Ontario & $30(34.5)$ & $12(28.6)$ & $42(34.1)$ & 0.61 \\
\hline Atlantic Canada & $18(20.7)$ & 5 (13.9) & $23(18.7)$ & 0.61 \\
\hline \multicolumn{5}{|l|}{ Distance to urban centre of $>250,000$} \\
\hline Located in urban centre & $22(25.3)$ & $13(36.1)$ & $35(28.5)$ & 0.35 \\
\hline$<250 \mathrm{~km}$ & $42(48.3)$ & $17(47.2)$ & $59(48.0)$ & 0.35 \\
\hline$\geq 250 \mathrm{~km}$ & $23(26.4)$ & $6(16.7)$ & $29(23.6)$ & 0.35 \\
\hline Has personal experience with serious illness or death of someone close & $70(80.5)$ & $15(79.0)$ & $98(79.7)$ & 0.46 \\
\hline \multicolumn{5}{|l|}{ Self-rated importance of spirituality } \\
\hline Somewhat important or important & $48(56.5)$ & $24(66.7)$ & $72(58.5)$ & 0.40 \\
\hline Neutral & $18(21.2)$ & $4(11.1)$ & $22(17.8)$ & 0.40 \\
\hline Somewhat unimportant or unimportant & $19(22.4)$ & $8(22.2)$ & $27(21.9)$ & 0.40 \\
\hline \multicolumn{5}{|l|}{ Years of professional experience } \\
\hline$\leq 10$ years & $13(14.9)$ & $8(22.2)$ & $21(17.1)$ & 0.41 \\
\hline $11-25$ years & $47(54.0)$ & $15(41.7)$ & $62(50.4)$ & 0.41 \\
\hline$\geq 25$ years & $27(31.0)$ & $13(36.1)$ & $40(32.5)$ & 0.41 \\
\hline Is a Certified Respiratory Educator & $76(88.4)$ & $16(84.2)$ & $105(86.1)$ & 0.26 \\
\hline Has attended workshops or professional education on palliative care & $32(36.8)$ & $18(51.4)$ & $50(40.7)$ & 0.26 \\
\hline \multicolumn{5}{|l|}{ Practice setting } \\
\hline Asthma/COPD/ Cough Clinic & $21(24.1)$ & $3(8.3)$ & $24(19.5)$ & NA \\
\hline Primary health care & $11(12.6)$ & $10(27.8)$ & $21(17.1)$ & NA \\
\hline Acute care & $17(19.5)$ & $4(11.1)$ & $21(17.1)$ & NA \\
\hline Home Care & $7(8.0)$ & $3(8.3)$ & $10(8.1)$ & NA \\
\hline Community Care & $6(6.9)$ & $2(5.6)$ & $8(6.5)$ & NA \\
\hline Other (including: mixed acute care and community, pharmacies, private practice) & $25(28.7)$ & $14(38.9)$ & $39(30.1)$ & NA \\
\hline \multicolumn{5}{|l|}{ Primary patient populations seen in practice (multiple allowed) } \\
\hline Chronic cough & $86(98.9)$ & $36(100)$ & $122(99.2)$ & NA \\
\hline COPD & $86(98.9)$ & $34(94.4)$ & $120(97.6)$ & NA \\
\hline Interstitial Lung Disease & $58(66.7)$ & $18(50.0)$ & $76(61.8)$ & NA \\
\hline Asthma & $42(48.3)$ & $21(58.3)$ & $63(52.3)$ & NA \\
\hline Lung Cancer & $33(37.9)$ & $15(41.7)$ & $48(39.0)$ & NA \\
\hline Pulmonary Hypertension & $21(24.1)$ & $6(16.7)$ & $27(22.0)$ & NA \\
\hline Lung Transplant & $14(16.1)$ & $3(8.3)$ & $17(13.8)$ & NA \\
\hline Cystic Fibrosis & $8(9.2)$ & $1(2.8)$ & $9(6.5)$ & NA \\
\hline
\end{tabular}

Note: NA, not available as cell counts of $<5$ precluded statistical analyses.

Respondents were distributed across Western Canada, Ontario, and Atlantic Canada, with close to half reporting residence outside of, but within 250 kilometres, of an urban centre with a population of 250,000 people or more. The majority (82.9\%) were seasoned health care professionals with 11 or more years of professional experience in practice settings that included respiratory disease such as COPD (98.9\%) and Interstitial Lung Diseases (66.7\%). Approximately $41 \%$ had attended workshops or professional education related to palliative care.

Respondents' current participation in palliative and end-of-life care is reported in Table 2. Again, no significant differences between the groups were identified and are not reported in the table. Close to three-quarters of respondents reported deaths from respiratory disease on their caseloads. Significant variability was noted in the frequency of having end-of-life discussions with patients. Only $17.1 \%$ of respondents reported that more than half of the patients for whom they cared had written advance care plans, although most respondents (65.0\%) indicated they were comfortable discussing advance care plans. The absence of an advance care plan was noted as an important barrier to having end-of-life discussions with their patients by $60.2 \%$ of respondents. The majority $(88.6 \%)$ did not discuss MAiD with their patients.

The most important patient- and family-related barriers reported by respondents to having end-of-life discussions involved: patient $(88.6 \%)$ and family $(91.7 \%)$ difficulty accepting prognosis, patient lack of capacity $(91.9 \%)$, lack of agreement amongst family members regarding palliative care $(91.1 \%)$, and patient difficulty accepting limitations and complications $(87.8 \%)$. In terms of provider barriers, three-quarters of respondents noted uncertainty about prognosis (76.4\%) and lack of training to have discussions $(74.0 \%)$. Lack of time (71.5\%) was the next most frequently reported barrier, followed by disagreement among team members (61.5\%). A significant difference between RTs and RHPs was noted in terms of the desire to maintain hope as a barrier to end-of-life discussions, with fewer RTs indicating that this was a barrier.

To examine variations in current palliative care services across jurisdictions, these analyses are reported by region in Table 3. No significant differences were identified between regions using Kruskal-Wallis ANOVA testing. The majority $(61.0 \%)$ of respondents disagreed with the statement "Patients with advanced respiratory illness received optimal end-of-life care." One-third of respondents $(32.5 \%)$ indicated the transition process between acute care, the community, and palliative care was smooth. Over half of respondents $(55.3 \%)$ agreed that palliative care was currently a role of respiratory educators. While there was near-unanimous agreement (95.1\%) that patients had a negative perception of the term palliative care, fewer $(58.5 \%)$ agreed that their colleagues had a negative perception of this term. Overall, $48 \%$ of respondents reported that there were dedicated supportive or palliative care services available to patients with advanced respiratory disease in their practices and a similar proportion believed that these services met most or all patient needs. Half of the respondents (51.1\%) currently worked collaboratively with palliative care services.

Table 4 displays respondent's perspectives on incorporating further focus on palliative care into the RHP role. Almost all (93.5\%) agreed that 
TABLE 2

Current respiratory health professional participation in palliative and end-of-life care

\begin{tabular}{|c|c|c|c|c|}
\hline & $\begin{array}{c}\text { Respiratory } \\
\text { Therapists }(n=87)\end{array}$ & $\begin{array}{c}\text { Other Respiratory } \\
\text { Professionals }(n=36)\end{array}$ & Overall $n=123$ & $p$ \\
\hline \multicolumn{5}{|c|}{ Frequency of deaths/month from respiratory disease on respondent caseload } \\
\hline 0 & $6(6.9)$ & $2(5.6$ & $8(6.5$ & NA \\
\hline$\leq 5$ & $50(57.5)$ & $22(61.1$ & $72(58.5$ & NA \\
\hline$>5$ & $16(18.4)$ & $3(8.3$ & $19(15.4$ & NA \\
\hline Unsure & $15(17.2)$ & $9(25.0$ & $24(19.5$ & NA \\
\hline \multicolumn{5}{|l|}{ Frequency of providing end-of-life care to respiratory patients } \\
\hline Once a month or more & $24(27.6)$ & $6(16.7$ & $30(24.4$ & NA \\
\hline Several times a year & $29(33.3)$ & $11(30.6$ & $40(32.5$ & NA \\
\hline Once a year & $13(14.9)$ & $3(8.3$ & $16(13.0$ & NA \\
\hline Never & $21(24.1)$ & $16(44.0$ & $37(30.1$ & NA \\
\hline \multicolumn{5}{|l|}{ Frequency of having end-of-life discussions with respiratory patients } \\
\hline Always/often & $17(19.5)$ & $9(25.0)$ & $26(21.1)$ & 0.75 \\
\hline Sometimes & $36(41.4)$ & $15(41.7)$ & $51(41.5)$ & 0.75 \\
\hline Rarely/never/not in my scope of practice & $34(27.6)$ & $12(33.3)$ & $46(37.4)$ & 0.75 \\
\hline \multicolumn{5}{|l|}{ Proportion of respiratory patients with Advance Care Plan (estimated) } \\
\hline$<25 \%$ & $35(40.2)$ & $16(44.4)$ & $51(41.5)$ & NA \\
\hline $26 \%-50 \%$ & $11(12.6)$ & $5(13.9)$ & $16(13.0)$ & NA \\
\hline$\geq 50 \%$ & $17(19.5)$ & $4(11.1)$ & $21(17.1)$ & NA \\
\hline Unsure & $24(27.6)$ & $11(30.6)$ & $35(28.5)$ & NA \\
\hline \multicolumn{5}{|l|}{ Level of comfort discussing Advance Care Plans } \\
\hline Comfortable & $56(64.4)$ & $24(66.7)$ & $80(65.0)$ & NA \\
\hline Neutral & $12(13.8)$ & $3(8.3)$ & $15(12.2)$ & NA \\
\hline Uncomfortable & $19(21.8)$ & $9(25.0)$ & $28(22.8)$ & NA \\
\hline \multicolumn{5}{|l|}{ Discuss MAiD with patients } \\
\hline Yes & $7(8.0)$ & $7(19.4)$ & $14(11.4)$ & 0.70 \\
\hline No & $80(92.0)$ & $29(80.6)$ & $109(88.6)$ & 0.70 \\
\hline \multicolumn{5}{|l|}{ Important patient and family barriers to end-of-life discussions } \\
\hline Patient difficulty accepting prognosis & $75(86.2)$ & $34(94.4)$ & $109(88.6)$ & 0.23 \\
\hline Patient difficulty accepting limitations and complications & $78(89.7)$ & $30(83.3)$ & $108(87.8)$ & 0.40 \\
\hline Family member difficulty accepting prognosis & $78(89.7)$ & $34(94.4)$ & $112(91.9)$ & 0.49 \\
\hline Patient lack of capacity & $78(89.7)$ & $35(97.2)$ & $113(91.9)$ & 0.16 \\
\hline Lack of agreement amongst family members regarding palliative care & $77(88.5)$ & $35(97.2)$ & $112(91.1)$ & 0.10 \\
\hline Language barrier & $67(77.0)$ & $31(86.1)$ & $98(79.7)$ & 0.25 \\
\hline No advance care plan & $48(55.2)$ & $26(72.2)$ & $74(60.2)$ & 0.08 \\
\hline \multicolumn{5}{|l|}{ Important provider barriers to end-of-life discussions } \\
\hline Uncertainty about prognosis & $65(74.7)$ & $29(80.6)$ & $94(76.4)$ & 0.49 \\
\hline Lack of training to have discussion & $68(78.2)$ & $23(63.9)$ & $91(74.0)$ & 0.10 \\
\hline Desire to maintain hope & $34(39.1)$ & $22(61.1)$ & $56(45.5)$ & NA \\
\hline Not part of my role/scope of practice & $25(28.7)$ & $14(38.9)$ & $39(31.7)$ & 0.48 \\
\hline Lack of time & $60(68.2)$ & $28(77.8)$ & $88(71.5)$ & 0.32 \\
\hline Disagreement among team members & $51(58.6)$ & $24(66.7)$ & $75(61.0)$ & 0.41 \\
\hline Own belief system & $17(19.5)$ & $10(27.8)$ & $27(22.0)$ & 0.32 \\
\hline
\end{tabular}

Note: NA, not available as cell counts of $<5$ precluded statistical analyses. MAiD, medical assistance in dying.

palliative care and management of advanced symptoms should be an integral role of the RE and that chronic disease management and palliative care can be offered at the same time $(91.1 \%)$. Most respondents $(66.7 \%)$ indicated that the best time to offer palliative care was at the diagnosis of advanced illness (MRC 4). Within this group of respondents, there was a high degree of interest in further training in palliative care. Because of cell sizes of $<5$ for each of the variables, only descriptives are reported.

\section{DISCUSSION}

As key members of the health care team, RHPs have significant influence over the quality of care and an emerging opportunity to influence quality exists in the area of care in advanced respiratory disease. Incorporating a more defined role in palliative care was seen by most respondents to this survey as a desirable evolution in professional responsibility, particularly given that deaths of respiratory patients were not uncommon on caseloads, and there was variability in access to palliative care services across Canada. Variability in RHP practice with respect to discussing preferences for end-of-life care was noted, as was the use of advance care plans. The most important patient-and familyrelated barriers to having end-of-life discussions included difficulty accepting prognosis, limitations, and complications, as well as patient lack of capacity. For providers, the most important barriers to having these discussions were lack of training, uncertainty about prognosis, and lack of time. Important opportunities to improve the quality of care at the end of life exist in closer collaboration between RHP and formal palliative services and participation in providing support patient transitions between settings. Chronic disease management and palliative care were not viewed by respondents as mutually exclusive foci of care, but could be integrated to better address the needs of patients.

Our findings support imperatives to incorporate a palliative approach into the care of patients with advanced respiratory disease, which have been framed from the perspectives of both justice and redressing health care disparities [30]. Applying the principle of justice means that appropriate palliative care support should be available to all patients with similar needs, irrespective of diagnosis [30, 32]. While the burden of advanced respiratory disease has been demonstrated to equal or surpass that of cancer $[39,40]$, patients with chronic lung disease have less access to and receive fewer palliative care services $[48,49]$. One strategy to address these disparities could involve engaging RHPs in a palliative care role.

One important component of incorporating palliative care principles into the practice of RHPs involves engaging in discussions related to 
TABLE 3

Perspectives on current respiratory palliative care services by region

\begin{tabular}{|c|c|c|c|c|c|}
\hline & $\begin{array}{c}\text { Western } \\
\text { Canada }(n=58)\end{array}$ & $\begin{array}{l}\text { Ontario } \\
(n=42)\end{array}$ & $\begin{array}{l}\text { Atlantic Canada } \\
\qquad(n=23)\end{array}$ & Overall & $p$ \\
\hline \multicolumn{6}{|c|}{ Patients with advanced respiratory illness receive optimal end-of-life care } \\
\hline Disagree & $38(65.5)$ & $22(52.4)$ & $15(65.2)$ & $75(61.0)$ & NA \\
\hline Neutral & 0 & 0 & 0 & 0 & NA \\
\hline Agree & $20(34.5)$ & $20(47.6)$ & $8(34.8)$ & $48(39.0)$ & NA \\
\hline \multicolumn{6}{|c|}{$\begin{array}{l}\text { Transition process is smooth between acute care, community care and } \\
\text { palliative care }\end{array}$} \\
\hline Disagree & $36(62.1)$ & $19(45.2)$ & 9 (39.1) & $64(52.0)$ & NA \\
\hline Neutral & 7 (12.1) & $8(19.0)$ & 4 (17.4) & $19(15.4)$ & NA \\
\hline Agree & $15(25.9)$ & $15(35.7)$ & $10(43.5)$ & $40(32.5)$ & NA \\
\hline \multicolumn{6}{|l|}{ Palliative care is currently a role of RHPs } \\
\hline Disagree & $22(37.9)$ & $19(45.2)$ & $7(30.4)$ & $48(39.0)$ & NA \\
\hline Neutral & $4(6.9)$ & $1(2.4)$ & $2(8.7)$ & $7(5.7)$ & NA \\
\hline Agree & $32(55.2)$ & $22(32.4)$ & $14(60.9)$ & $68(55.3)$ & NA \\
\hline \multicolumn{6}{|c|}{ Patients have a negative perception of the term palliative care } \\
\hline Disagree & $2(3.4)$ & $3(2.4)$ & $1(4.3)$ & $6(4.9)$ & NA \\
\hline Agree & $56(96.6)$ & $39(92.9)$ & $22(95.7)$ & $117(95.1)$ & NA \\
\hline \multicolumn{6}{|c|}{ Colleagues have a negative perception of the term palliative care } \\
\hline Disagree & $25(43.1)$ & $16(38.1)$ & $10(43.5)$ & $51(41.5)$ & 0.86 \\
\hline Agree & $33(56.9)$ & $26(61.9)$ & $13(56.5)$ & $72(58.5)$ & 0.86 \\
\hline \multicolumn{6}{|c|}{$\begin{array}{l}\text { Dedicated supportive or palliative care services for patients with } \\
\text { advanced respiratory disease }\end{array}$} \\
\hline Yes & $25(43.1)$ & $20(47.6)$ & $14(60.9)$ & $59(48.0)$ & NA \\
\hline No & $19(32.8)$ & $9(21.4)$ & $7(30.4)$ & $35(28.5)$ & NA \\
\hline Unsure & $14(24.1)$ & $13(44.8)$ & $2(8.7)$ & $29(23.6)$ & NA \\
\hline \multicolumn{6}{|c|}{ Extent to which existing palliative care services meet patient needs } \\
\hline No services or does not meet needs at all & $7(12.2)$ & $6(14.3)$ & $2(8.7)$ & $15(12.2)$ & NA \\
\hline Meets needs to some extent & $15(25.9)$ & $8(19.0)$ & $3(13.0)$ & $26(21.1)$ & NA \\
\hline Meets most or all needs & $26(44.8)$ & $16(38.1)$ & $15(65.2)$ & $57(46.3)$ & NA \\
\hline Unsure & $10(17.2)$ & $12(28.6)$ & $3(13.0)$ & $25(20.3)$ & NA \\
\hline \multicolumn{6}{|l|}{ RE works collaboratively with PC services } \\
\hline Yes & $32(55.2)$ & $19(45.2)$ & $12(52.2)$ & $63(51.2)$ & 0.62 \\
\hline No & $26(44.8)$ & $23(54.8)$ & $11(47.8)$ & $60(48.8)$ & 0.62 \\
\hline
\end{tabular}

Note: NA, not available as cell counts of $<5$ precluded statistical analyses. RHP, Respiratory Health Professionals; RE, Respiratory Educator; PC, Palliative Care.

\section{TABLE 4}

Perspectives on incorporating further palliative care focus into the respiratory health professional (RHP) role

\begin{tabular}{|c|c|c|c|}
\hline & $\begin{array}{c}\text { Respiratory } \\
\text { Therapists }(n=87)\end{array}$ & $\begin{array}{c}\text { Other respiratory } \\
\text { professionals }(n=36)\end{array}$ & $\begin{array}{l}\text { Overall } \\
(n=123)\end{array}$ \\
\hline \multicolumn{4}{|c|}{ Palliative care and management of serious symptoms should be an integral role of RHPs } \\
\hline Disagree & $3(3.4)$ & $2(5.6)$ & $5(4.1)$ \\
\hline Neutral & $1(1.1)$ & $2(5.6)$ & $3(2.4)$ \\
\hline Agree & $83(95.4)$ & $32(88.8)$ & $115(93.5)$ \\
\hline \multicolumn{4}{|c|}{ Chronic disease management and palliative care can be offered to a patient at the same time } \\
\hline Disagree & $6(6.9)$ & $3(8.3)$ & $9(7.3)$ \\
\hline Neutral & $2(2.3)$ & 0 & $2(1.6)$ \\
\hline Agree & $79(90.8)$ & $33(91.7)$ & $112(91.1)$ \\
\hline \multicolumn{4}{|c|}{ When is the best time to offer palliative care services for respiratory patients? } \\
\hline At the time of diagnosis & $4(4.6)$ & $3(8.3)$ & $7(5.7)$ \\
\hline At diagnosis of moderate illness (MRC 3 ) & $9(10.3)$ & $4(30.8)$ & $13(10.6)$ \\
\hline At diagnosis of advanced illness (MRC 4) & $58(66.7)$ & $12(63.2)$ & $82(66.7)$ \\
\hline In the last $6-12$ months of life & $9(10.3)$ & $1(2.8)$ & $10(8.1)$ \\
\hline In the last 3-6 months of life & $6(4.9)$ & $4(11.1)$ & $10(8.1)$ \\
\hline In the last month of life & $1(1.1)$ & 0 & $1(0.8)$ \\
\hline \multicolumn{4}{|l|}{ Interest in palliative care training } \\
\hline Yes & 79 (91.9) & $30(83.3)$ & $109(89.3)$ \\
\hline Unsure & $7(8.1)$ & $5(13.9)$ & $1(0.8)$ \\
\hline No & 0 & $1(2.8)$ & $12(9.8)$ \\
\hline
\end{tabular}

future care and care preferences with patients with advanced respiratory disease. Patient and family difficulties in accepting prognosis and limitations were found to be an important barrier by respondents to having these discussions. This challenge may be due, in part, to the insufficient disease-specific knowledge and health literacy on the part of patients and family members, including the usual course of the illness. Several studies have reported inadequate knowledge was common with both respiratory patients and family members $[50,51]$. In COPD, a higher level of knowledge was associated with better adaptation to the illness [50]. Given that patient and family education is a primary role of most RHPs, additional focus on assessing level of knowledge about the disease may help to mitigate the difficulties that have been reported in accepting prognosis. 
Uncertainty about prognosis was also reported as an important barrier to engaging in end-of-life discussions. While prognostic uncertainty remains a challenge in advanced respiratory disease [52], a focus on the actual needs of the individual patient, rather than their prognosis, can allow for the incorporation of palliative care principles such as management of distressing symptoms at any time in their care trajectory.

Lack of capacity also served as a barrier to engaging in end-of-life discussions for many respondents. Growing evidence suggests an association between cognitive impairment and COPD [5, 53, 54], which has been attributed to the hypoxemia seen in some patients with COPD affecting the synthesis of neurotransmitters such as acetylcholine [53]. A systematic review [55] found considerable impairment of both memory and attention in patients with COPD, which may be worse in patients with advanced disease. While lack of capacity can be a clear barrier to engaging in end-of-life discussions with patients with advanced respiratory disease, RHPs who understand that cognitive impairment may be an outcome may serve their patients well by having advance care planning discussions earlier, rather than later, in the course of care. A minority of respondents to this survey, however, were able to report that $50 \%$ of more of the patients on their caseloads with advanced respiratory disease had advance care plans.

Maddocks et al. [56] have called for new models of care integrating respiratory medicine, primary care, and rehabilitation services, which could be further enhanced by integrating palliative care principles [41]. The successful integration of chronic disease management and palliative care within a seamless model of respiratory care has been previously reported [35-40], although widespread adoption of these models will require major reforms in policy, resource allocation, and practice. Four central challenges to advancing palliative care reforms in general have been noted: (i) limited knowledge about palliative care in health care, including lack of training; (ii) cultural beliefs about palliative care; (iii) payment/reimbursement for palliative care services; and (iv) limited public awareness and understanding of palliative care [57]. To transition to new models of care for patients with advanced respiratory disease, these same issues will require concerted and ongoing advocacy on the part of health care providers, patients and families, and charitable organizations.

\section{Limitations}

This cross-sectional survey was designed to explore the current and desired roles of RHPs in palliative care to inform the feasibility of future research in this area. While our survey findings included the responses of 123 RHPs representing most regions of Canada (with the exception of Quebec) and reflect diverse population densities, the findings of this survey are not generalizable to the entire population of Canadian RHPs. The RESPTREC database was selected because it potentially covered a wide cross-section of Canadian respiratory health professionals, with the exception of those in Quebec. This database covered an 18-year span of time and likely contained contacts no longer practicing in the area of respiratory health, limiting our ability to construct a contained sampling frame. Soliciting respondents from provincial or national professional licensing bodies may have provided a more reliable sampling frame. Response bias was likely in that RHPs with a pre-existing interest in palliative care chose to complete the survey. The use of nonparametric analysis was appropriate for the relatively small sample size, but no statistically significant differences could be detected between either professional groups or geographic regions. Given the absence of validated surveys addressing the research question, survey items had to be developed by the authors to capture data most salient to the objectives.

\section{Implications for clinical practice}

For RHPs who care for patients with advanced respiratory disease, care should be taken to identify needs that can be best served using a palliative care approach. Because this holistic approach encompasses attention to psychological distress, spiritual distress, and social needs, as well as physical issues, some respiratory services may not feel adequately resourced to respond effectively to the range of needs identified. Documentation of patient needs can build the evidentiary base typically required by funders to reallocate resources. Building collaborations with other existing services to address these needs once they have been identified can help enormously to ensure a high quality of care. Creating and taking advantage of learning opportunities to build skills and comfort in using a palliative approach will also be of benefit to RHPs and the patients they serve. Learning from the best practices of other RHPs, across Canada and globally, who care for patients with advanced respiratory disease has significant potential to improve care.

\section{CONCLUSIONS}

The quality of care for patients with advanced respiratory disease can be enhanced by integrating principles of palliative care into chronic disease management [55]. Because many RHPs already work in interdisciplinary teams, they can take on leadership roles in promoting the need for palliative care on their services. RHPs can help to address the gaps in care identified in this exploratory survey, including limited access to palliative care and difficult transitions through collaboration, training, and research.

\section{ACKNOWLEDGMENTS}

We wish to thank Lori Kleiboer and Trent Litzenberger at RESPTREC for allowing us to distribute the surveys through their database. We also acknowledge the contributions of Thilina Bandara in the survey construction and Rana Masud for statistical consultation.

\section{Contributors}

DG and JP contributed to the conception or design of the work, as well as the acquisition, analysis, or interpretation of the data. DG and JP were involved in drafting and commenting on the paper and have approved the final version.

\section{Funding}

This study did not receive any specific grant from funding agencies in the public, commercial, or not-for-profit sectors.

\section{Competing interests}

All authors have completed the ICMJE uniform disclosure form at www. icmje.org/coi_disclosure.pdf and declare: no financial relationships with any organizations that might have an interest in the submitted work in the previous 3 years; no other relationships or activities that could appear to have influenced the submitted work.

\section{REFERENCES}

1. Statistics Canada. The 10 leading causes of death, 2016. Available at: https://www150.statcan.gc.ca/t1/tbl1/en/cv.action?pid=1310039401 (Accessed July 17, 2019).

2. The Conference Board of Canada, 2012. Report by Theriault L, Hermus G, Goldfarb D, Stonebridge C, Bounajm F. Cost risk analysis for chronic lung disease in Canada. Available at: https://www.conferenceboard.ca/ elibrary/abstract.aspx?did=4585

3. Hutchinson JP, McKeever TM, Fogarty AW, Navaratam V, Hubbard RB. Increasing global mortality from idiopathic pulmonary fibrosis in the twenty-first century. Ann Am Thorac Soc 2014;11(8): 1176-85. doi: 10.1513/AnnalsATS.201404-145OC

4. Lau EMT, Giannoulatou E, Celermajer DS, Humbert S. Epidemiology and treatment of pulmonary arterial hypertension. Nature Rev Cardiol 2017;14: 603-14. doi: 10.1038/nrcardio.2017.84

5. Stephenson AL, Sykes J, Stanojevic S, et al. Survival comparison of patients with cystic fibrosis in Canada and the United States: A population-based cohort study. Ann Intern Med 2017;166(8): 537-46. doi: 10.7326/M16-0858

6. Narsavage GL, Chen Y-J, Korn B, Elk R. The potential of palliative care for patients with respiratory diseases. Breathe 2016;13(4): 278-89. doi: $10.1183 / 20734735.014217$

7. Statistics Canada. Deaths and causes of death, 2017. Release date: 201811-29. Available at: https://www150.statcan.gc.ca/n1/daily-quotidien/ 181129/t001g-eng.htm (Accessed June 21, 2019).

8. Murtagh FEM, Bausewein C, Verne J, Groenveld EI, Kaloki YE, Higginson IJ. How many people need palliative care? A study developing and comparing methods for population-based estimates. Pall Med 2014;28(1): 49-58. doi: 10.1177/0269216313489367 
9. Canadian Institute for Health Information. Access to palliative care in Canada; 2018. Available at: https://www.cihi.ca/sites/default/files/document/access-palliative-care-2018-en-web.pdf (Accessed April 21, 2019).

10. International Association of Hospice and Palliative Care. Palliative care definition. Available at: https://hospicecare.com/what-we-do/projects/consensusbased-definition-of-palliative-care/definition/ (Accessed April 19, 2019).

11. Bakitas MA, Tosteson TD, Li Z, et al. Early versus delayed initiation of concurrent palliative oncology care: Patient outcomes in the ENABLE III randomized controlled trial. J Clin Oncol 2015;33(13): 1438-45. doi: 10.1200/JCO.2014.58.6362

12. Temel JS, Greer JA, Muzikansky A, et al. Early palliative care for patients with metastatic non-small-cell lung cancer. N Engl J Med 2010;363: 733-42. doi: 10.1056/NEJMoa1000678

13. McNamara BA, Rosenwax LK, Murray K, Currow DC. Early admission to community-based palliative care reduces use of emergency departments in the ninety days before death. J Palliat Med 2013;16(7): 774-9. doi: $10.1089 /$ jpm.2012.0403

14. Seow $\mathrm{H}$, Barbera L, Pataky R, et al. Does increasing home care nursing reduce emergency visits at the end of life? A population-based cohort study of cancer decedents. J Pain Symptom Manage 2016;51(2): 204-12. doi: 10.1016/j.painsymman.2015.10.008

15. Spilsbury K, Rosenwax L, Arendts G, Semmens JB. The impact of community-based palliative care on acute hospital use in the last year of life is modified by time to death, age and underlying cause of death. A population-based retrospective cohort study. PLoS One 2017;12(9): e0185275. doi: 10.1371/journal/pone.0185275

16. Ranganathan A, Dougherty M, Waite D. Casarett D. Can palliative home care reduce 30-day readmissions? Results of a propensity score matched cohort study. J Palliat Med 2013;16(10): 1290-3. doi: 10.1089/ jpm.2013.0213

17. Enguidanos S, Vesper E, Lorenz K. 30-day re-admissions among seriously ill older adults. J Palliat Med 2012;15(12): 1356-61. doi: 10.1089/ jpm.2012.0259

18. Gainza-Miranda D, Sanz-Peces EM, Alonso-Babarro A, et al. Breaking barriers: Prospective study of a cohort of advanced chronic obstructive pulmonary disease patients to describe their survival and end-of-life palliative care requirements. J Palliat Med 2019;22(3): 290-6. doi: 10.1089/ jpm.2018.0363

19. Tavares N, Jarrett N, Hunt K, Wilkinson T. Palliative and end-of-life conversations in COPD: A systematic review. ERJ Open Res 2017;3: 00068 2016. doi: $10.1183 / 23120541.00068-2016$

20. Harrington SE, Rogers E, Davis M. Palliative care and chronic obstructive lung disease: Where the lines meet. Curr Opin Pulm Med 2016;23(2): 154-60. doi: 10.1097/MCP.0000000000000358

21. Bloom CI, Slaich B, Morales DR, Smeeth L, Stone P, Quint JK. Low uptake of palliative care for COPD patients within primary care in the UK. Eur Resp J 2018;51: 1701879. doi: 10.1183/13993003. 01879-2017

22. Rush B, Hertz P, Bond A, McDermid RC, Celi LA. Use of palliative care in patients with end-stage COPD and receiving home oxygen: National trends and barriers to care in the United States. Chest 2017;15: 41-6. doi: 10.1016/j.chest.2016.06.023

23. Canadian Institute for Health Information. Health care use at the end of life in Western Canada. Ottawa: Canadian Institute for Health Information; 2011.

24. Canadian Institute for Health Information. Health care use at the end of life in Atlantic Canada. Ottawa: Canadian Institute for Health Information; 2011.

25. Goodridge D, Lawson J, Duggleby W, Marciniuk D, Rennie D, Stang MR. Health care utilization of patients with chronic obstructive pulmonary disease and lung cancer in the last 12 months of life. Resp Med 2008;102(6): 885-91. doi: 10.1016/j.rmed,2008.01.007

26. Curtis JR. Palliative care and end-of-life care for patients with severe COPD. Eur Respir J 2008;32(3): 796-803. doi: 10.1183/09031936. 00126107

27. Cohen J, Benaert K, Van den Block L, et al. Differences in place of death between lung cancer and COPD patients: A 14-country study using death certificate data. NPJ Prim Care Resp Med 2017;27(1):14. doi: $10.1038 / \mathrm{s} 41533-017-0017-\mathrm{y}$

28. Kreuter M, Bendstrup E, Russel A-M, et al. Palliative care in interstitial lung disease: Living well. Lancet Respir Med 2017;5(12): 968-80. doi: 10.1016/S2213-2600(17)30383-1

29. Knauft E, Nielsen EL, Engelberg RA, Patrick DL, Curtis JR. Barriers and facilitators to end-of-life care communication for patients with COPD. Chest 2005;12(6): 2188-96. doi: 10.1378/chest.127.6.2188
30. Brown CE, Jecker NS, Curtis JR. Inadequate palliative care in chronic lung disease: An issue of health care inequality. Ann Am Thorac Soc 2016;13(3): 311-6. doi: 10.11513/Annals/ATS.201510-666PS

31. Rocker G, Downar J, Morrison S. Palliative care for chronic illness: Driving change. CMAJ 2016;188(7-18): E493-8. doi: 10.1503/cmaj.151454

32. Quill TE, Abernethy AP. Generalist plus specialist palliative care Creating a more sustainable model. N Engl J Med 2013;368: 1173-5. doi: 10.1056/NEJMp1215620

33. Murray SA, Kendall M, Boyd K, Sheikh A. Illness trajectories and palliative care. BMJ 2005;330(7498): 1007-11. doi: 10.1136/bmj.330. 7498.1007

34. Smith LE, Moore E, Ali I, Smeeth L, Stone P, Quint JK. Prognostic variables and scores identifying the end of life in COPD: A systematic review. Int J Chron Obstruct Pulmon Dis 2017;12: 2239-56. doi: 10.2147/COPD.S137868

35. Zimmerman C, Swami N, Krzyzanowska M, et al. Perceptions of palliative care among patients with advanced cancer and their caregivers. CMAJ 2016;188(10): E217-27. doi: 10.1503/cmaj.151171

36. Hui D, Kim SH, Kwon JH, et al. Access to palliative care among patients treated at a comprehensive cancer centre. Oncologist 2012;17(2): 1574-80. doi: 10.1634/theoncologist,2012-0192

37. Fromer L. Implementing chronic care for COPD: Planned visits, care coordination and patients empowerment for improved outcomes. Int J Chronic Obstruct Pulmon Dis 2011;6: 605-14. doi: 10.2147/COPD. S24692

38. Booth S, Moffat C, Farquhar M. Developing a breathlessness intervention service for patients with palliative and supportive care needs, irrespective of diagnosis. J Palliat Care 2011;27(1): 28-36. doi: 10.1177/ 082585971102700106

39. Bausewein C, Schunk M, Schumacher P, Dittmer J, Bolzani A, Booth S. Breathlessness services as a new model of support for patients with respiratory disease. Chron Resp Dis 2018;15(1): 48-59. doi: 10.1177/ 1479972317721557

40. Smallwood N, Thompson M, Warrender-Sparkes M, et al. Integrated respiratory and palliative care may improve outomes in advanced lung disease. ERJ Open Res 2018;4: 00102-2017. doi: 10.1183/23120541.00102-2017

41. Rocker GM, Amar C, Laframboise WL, burns J, Verma JY. Spreading improvements for advanced COPD care through a Canadian collaborative. Int J Chron Obstruct Pulmon Dis 2017;12: 2157-64. doi: 10.2147/ COPD.S140043

42. Verma JY, Amar C, Sibbald S, Rocker GM. Improving care for advanced COPD through practice change: Experiences of participation in a Canadian spread collaborative. Chron Resp Dis 2018;15(1): 5018. doi: $10.1177 / 1479972317712720$

43. Government of Canada. Medical assistance in dying. Available at: https://www.canada.ca/en/health-canada/services/medical-assistancedying.html (Accessed July 7, 2019).

44. Government of Canada. Fourth interim report on medical assistance in dying in Canada. Available at: https://www.canada.ca/en/health-can$\mathrm{ada} /$ services/publications/health-system-services/medical-assistance-dying-interim-report-april-2019.html (Accessed July 7, 2019).

45. Canadian Network for Respiratory Care. National learning objectives for respiratory educators. 2019. Available at: http://cnrchome.net/ assets/2019-learning-objectives-for-respiratory-educators.pdf

46. Boulet LP, Bourbeau J, Skomro R, et al. Major care gaps in asthma, sleep, and chronic obstructive pulmonary disease: A road map for knowledge translation. Can Respir J 2013;20: 265-9. doi: 10.1155/2013/496923

47. Boulet LP. Asthma education: An essential component in asthma management. Eur Respir J 2015: 1262-4. doi: 10.1183/13993003.01303-2015

48. Gore JM, Brophy CJ, Greenstone MA. How well do we care for patients with end-stage chronic obstructive puolmonary disease (COPD)? A comparison of palliative care and quality of life in COPD and lung cancer. Thorax 2000;55: 1000-6. doi: 10.1136/thorax.55.12.1000 (Accessed July 9, 2019).

49. Schroedl CJ, Yount SE, Szmuilowicz E, Hutchiinson PH, Rosenberg SR, Kalhan R. A qualitative study of unmet healthcare needs in chronic obstructive pulmonary disease: A potential role for specialist palliative care? Ann Am Thorac Soc 2014;11: 1433-8. doi: 10.1513/Annals ATS.201404-155BC

50. Boot CR, van der Gulden JW, Vercoulen JH, et al. Knowledge about asthma and COPD: Associations with sick leave, health complaints, functional limitations, adaptations and perceived control. Patient Educ Couns 2005;59(1): 103-9. doi: 10.1016/j.pec.2004.10.007

51. Nakken N, Janseen DJ, van den Bogaart EH, et al. Knowledge gaps in patients with COPD and their proxies. BMC Pulm Med 2017;17: 13. doi: $10.1186 / \mathrm{s} 12890-017-0481-8$ 
52. Ley B, Collard HR, King TE, Jr Clinical course and prediction of survival in idiopathic pulmonary fibrosis. Am J Respir Crit Care Med 2011;183: 431-40. doi: 10.1164/rccm.201006-0894CI

53. Dodd JW. Lung disease as a determinant of cognitive decline and dementia. Alzheimers Res Ther 2015;7: 32. doi: 10.1186/s13195. 0150116-3

54. Heaton RK, Grant I, McSweeny AJ, Adams KM, Petty TL. Psychologic effects of continuous and nocturnal oxygen therapy in hypoxemic chronic obstructive pulmonary disease. Arch Intern Med 1983;143(10): 1941-7.
55. Torres-Sanchez I, Rodriguez-Alzueta E, Cabrera-Martos I, et al. Cognitive impairment in COPD: A systematic review. J Bras Pneumol 2015;41: 182-90. doi: 10.1590/S1806-37132015000004424

56. Maddocks M, Lovell N, Booth S, Man WD, Higginson I. Palliative care and management of troublesome symptoms for people with chronic obstructive pulmonary disease. Lancet 2017;390:988-1002. doi: 10.1016/ S0140-6736(17)32127-X

57. Schreibeis-Baum HC, Xenakis LE, Chen EK, et al. A qualitative inquiry on palliative and end-of-life care policy reform. J Palliat Med 2016;19(4): 400-7. doi: $10.1089 /$ jpm.2015.0296 